\title{
DIFERENTES FAZERES, DIFERENTES SABERES : A AÇÃO DE MONITORES EM ESPAÇOS NÃO ESCOLARES ${ }^{1}$
}

Differents tasks, differents knowledges: the supervisor's action into informal education.

Silvania Sousa do Nascimento² (Faculdade de Educação, UFMG, Brasil)

Contato : Departamento de Métodos e Técnicas de Ensino

Av. Antônio Calos, 6627 Campus Pampulha

CEP 31 270-901 Fone (0XX) 31- 3499-6207

silsousa@fae.ufmg.br

\begin{abstract}
Annick Weil-Barais (Laboratoire Déterminants Culturels et Sociaux des Conduites, Université d'Angers, França) Dominique Davous (Groupe de Recherche en Didactique de la Chimie-GREDIC, Université Pierre et Marie Curie, Paris 6, França)
\end{abstract}

\section{RESUMO:}

Este artigo discute a metodologia utilizada para caracterizar os saberes práticos e teóricos de um monitor em uma seqüência de construção de um micro foguete durante uma colônia de férias. São propostos dois tipos de análise: uma global da seqüência que visa o estabelecimento de sua cronologia e outra proposicional para a categorização do discurso do monitor em dois episódios. Na primeira análise, as ações e tarefas enunciadas pelo monitor constituem o protocolo efetivo da seqüência e evidencia sua organização no tempo e no espaço assim como a gestão de diferentes fazeres do monitor. Na segunda, encontramos indicações de saberes e estratégias centrados na gestão de configurações espaciais múltiplas, na nominação e na qualificação dos elementos constitutivos do objeto técnico.

Palavras chaves: educação não formal, objeto técnico, análise de discurso.

\section{ABSTRACT:}

This article discuses the methodology to characterize the practical and theoretical knowledge in the construction of a small-rocket during a holiday camp. Two types of analysis were suggested: a global analysis of sequences which aims to stabile the chronology of the process and another, grammatical, which aims to categorize the discourses of the supervisor in two differents episodes. From the actions and tasks enumerated by the supervisor constitute the effective protocol of the sequence and put in to evidence its organization in time and space. This analysis also revels differents "supervisor's tasks". The second analysis shows of knowledge and strategy presented in the following aspects: management of multiple spatial configurations, denomination and qualifications of elements which constitutes the technical object.

Keys words: informal education, technical object, analyze of discourse.

${ }^{[1]}$ Silvania S. Nascimento, et al. Diferentes fazeres, diferentes saberes : a ação de monitores em espaços não escolares.

${ }^{2[2]}$ Apoio CAPES 


\section{Introdução}

As práticas educativas que ocorrem em espaços não escolares como os museus e parques de ciências, os clubes de ciências, as associações de bairro são constituídas por sistemas complexos de interação. Neste artigo apresentamos uma dessas práticas particularmente atuante no contexto francês, a animação científica, considerada um sistema de mediação da cultura científica e tecnológica (Giordan et al., 1993). Essas práticas educativas utilizam modelos pedagógicos freqüentemente pertencentes à educação não formal e, em geral, são descritas por seus aspectos institucionais, objetivos declarados, conteúdos propostos sem serem tomados como práticas discursivas.

Propomos estudar o discurso do monitor sob os aspectos da organização da ação e da prática discursiva propostas em uma seqüência de construção de um objeto técnico. A hipótese que norteia nossa análise é que o discurso do monitor, durante a seqüência, é um indicador de um saber profissional caracterizado por Raisky (1996: 52) como um saber ${ }^{3[3]}$ inscrito dentro de uma lógica de ação e orientado por valores e finalidades explícitos de uma realidade sociocultural. Esse saber profissional realiza a integração de saberes de naturezas prática e teórica, ligados por interrelações específicas que definem o ofício ou a profissão. Em vista de um modelo analítico, colocaremos de um lado saberes teóricos definidores do quadro de referência tecnológico e científico da ação, e de outro lado saberes práticos que, por sua vez, definem o quadro de coordenação operacional da ação. Além desses, existem outros saberes adquiridos ao longo da história socio-profissional do indivíduo que não serão analisados neste artigo. Ao analisarmos uma prática social, as profissionais em particular, podemos dizer que existem práticas sociais de referencia ${ }^{4[4]}$ reguladoras das relações de força entre esses diferentes saberes (Cf figura 1).

Figura 1: Diferentes Saberes que constituem um saber profissional segundo Raisky (1996)

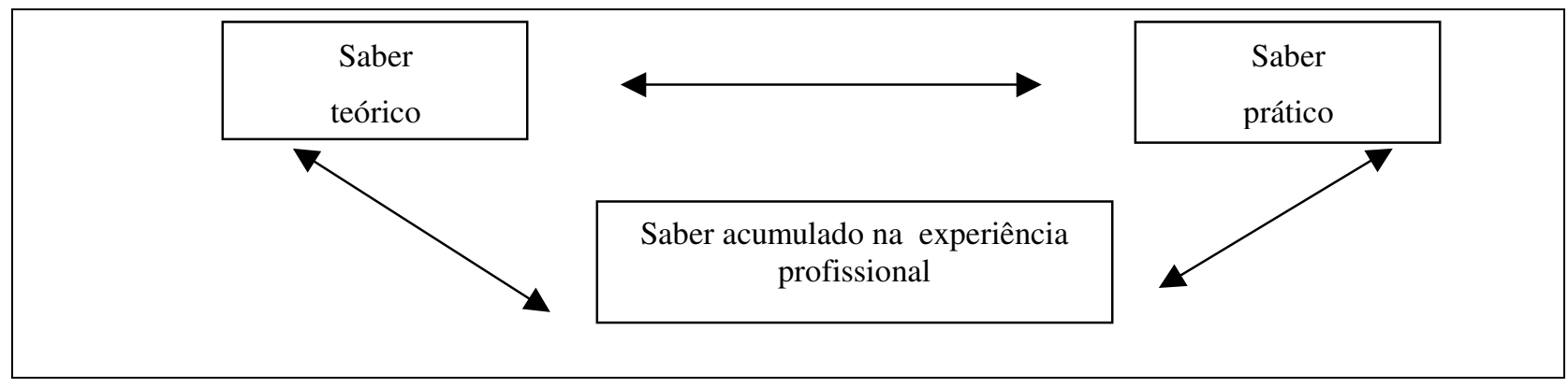

${ }^{[3]}$ Utilizamos a distinção entre saber e conhecimento sendo que o primeiro pertence ao indivíduo e lhe permite agir sobre os objetos, enquanto o segundo pertence a um determinado grupo social e é indiretamente ligada ao sujeito. Grize (1996:119)

${ }^{[4]}$ Martinand (1986) ao analisar o desenvolvimento de projetos pedagógicos no ensino médio definiu uma Prática Social de Referência pelo quadro socio-profissional utilizado como definidor dos objetivos de construção de um currículo. 
Nosso objetivo é, primeiramente, discutir a metodologia utilizada para descrever e caracterizar a ação do monitor centrada na análise de saberes práticos, isto é, saberes que organizam os procedimentos de execução de tarefas, de ações sobre os objetos, no tempo e no espaço. Em um segundo momento identificamos a natureza do saber teórico em jogo no discurso do monitor durante a seqüência.

\section{Metodologia de análise da seqüência}

O estudo que apresentamos foi desenvolvido segundo um quadro teórico etnográfico (Plety, 1993) em uma associação ${ }^{5}$ de cultura científica e tecnológica francesa, a Association Nationale Sciences Techniques Jeunesse, ANSTJ (Gautier, 1989). A seqüência analisada foi conduzida por dois monitores durante uma colônia de férias de uma semana em Franclens (Haute-Savoie, França) no verão de 1997. Uma dezena de crianças de 9 à 11 anos elaboraram o projeto, construíram e lançaram um micro foguete em uma seqüência de 8 horas dividida em quatro seções de trabalho. Os monitores observados receberam uma formação específica isomorfa, isto é, baseada em um protocolo prescrito da configuração espacial e temporal de possíveis cenários característicos da associação. Eles são jovens de 20 anos que possuem uma formação universitária correspondente aos dois primeiros anos das carreiras científicas e tecnológicas $(\mathrm{BAC}+2)$. O corpus analisado foi composto dos dados recolhidos através da observação direta do pesquisador (caderno de notas), da transcrição do registro de áudio e vídeo e das produções escritas dos participantes relativas as interações verbais e não verbais de apenas um dos monitores.

\subsection{O estabelecimento de uma cronologia da seqüência : o protocolo efetivo}

A primeira fase de análise da seqüência procurou definir a cronologia estabelecida pelo monitor. Nós utilizamos dois critérios para a decomposição da seqüência: a configuração espacial das interações e a atividade de referência conduzida a partir da enunciação de tarefas.

\subsubsection{A configuração espacial das interações}

Nós definimos a configuração espacial como a ocupação do espaço físico e a utilização ou não pelo monitor de elementos do cenário: disposição de postos de trabalhos (serraria, colagem, pintura), utilização de cartazes e maquetes, entre outros. Esta configuração pode evoluir no tempo e ela nos informa a organização espacial das interações pretendidas pelo monitor: exposição, discussão em pequenos grupos, discussão em dupla, trabalho cooperativo. Em nossa pesquisa em espaços não escolares definimos cinco tipos de configurações: Configuração Livre (CL), Organização Linear (OL), Organização Circular (OC), Organização em duplas de participantes (OD) e Organização centrada em uma pessoa ou objeto (OU)

[5] Uma associação de cultura científica e tecnológica, no contexto francês, é um organismo não governamental sem fins lucrativos regido pela Lei 1901. 
(Nascimento, 1999). Na fotografia 01 mostramos um exemplo da organização centrada no objeto (OU) bem característica da atividade de construção de um objeto técnico.

Inserir fotografia

Fotografia 01: Os monitores demonstram o funcionamento de uma bomba de vácuo (objeto central) e os participantes observam

\subsubsection{A atividade de referência conduzida pelo monitor}

Nossa atividade de referência é a construção e o lançamento do micro foguete. Este é um artefato balístico composto de um corpo cilíndrico de 30 centímetros, um sistema de aletas direcionais (em geral 4), uma ogiva, um propulsor movido a pólvora seca de dois tempos, um faiscador, um sistema elétrico de disparo a distância e um pára-quedas. O que diferencia a classificação - micro, mini ou foguete - é a potência de seu sistema de propulsão sem o qual um foguete seria um mero rojão. O sistema de propulsão de baixa potência foi desenvolvido nos Estados Unidos por grupos de trabalho ligados à pesquisa aeroespacial visando o lançamento de balões atmosféricos. Nos anos setenta, para satisfazer a curiosidade de jovens sobre a pesquisa aeroespacial, o Centro Nacional de Estudos Espaciais (CNES) importa esse sistema para a França. Alguns clubes de Ciências, compostos principalmente de engenheiros do CNES, organizaram nesta época a associação nacional (ANSTJ) o que permitiu a divulgação e a regulamentação do lançamento de artefatos aéreos assim como o controle do espaço aéreo para lançamentos esportivos. A venda dos propulsores (Koudou e Mouflon) é controlada pelo CNES e eles são cedidos gratuitamente aos clubes filiados à ANSTJ. Somente em 1994, os propulsores com carga explosiva inferior a 10 gramas foram considerados artefatos para divertimento sendo liberada sua comercialização.

Um micro foguete possui um propulsor de até 500 gramas de pólvora dimensionado de modo que a primeira explosão propulsione o artefato que pode atingir, em média, 15 metros de altura. A segunda explosão pressiona a ogiva e libera o pára-quedas possibilitando a recuperação do artefato. O sistema de disparo a distância é composto de um faiscador (100 mA ) ligado a uma bateria de $12 \mathrm{~V}$ e deve, por segurança, ser manuseado a uma distância mínima de 20 metros entre a linha de lançamento e a caixa de controle de disparo ou disparador -chave elétrica- (ANSTJ, 1997). Estes elementos técnicos compõem os indicadores léxicos para análise do discurso dos participantes. O conhecimento físico envolvido na atividade fazem parte dos Princípios da Mecânica Clássica.

Assim, uma análise preliminar da atividade de referência nos permitiu identificar quatro etapas da seqüência: apresentação, construção, lançamento e conclusão (Cf. quadro 1). 
Quadro 1: Etapas da seqüência

A. Apresentação $\rightarrow$ Introdução da seqüência a partir da apresentação dos atores até a enunciação das etapas de construção.

B. Construção $\rightarrow$ Elaboração do projeto de construção até a finalização do objeto.

C. Lançamento $\rightarrow$ Verificação e teste do micro foguete.

D. Conclusão $\rightarrow$ Discussão final da seqüência e recuperação do objeto.

No interior das etapas, a seqüência foi dividida em episódios tomando como referência o processo de transformação do objeto técnico (propulsor, lançamento do propulsor, projeto de construção, ogiva, decoração, teste). Nesta seqüência dezesseis episódios foram identificados através da análise das tarefas enunciadas nos turnos de fala ou nos atos comunicativos (gestos e manipulação de objetos) do monitor e/ou dos participantes que indicavam a evolução do processo de transformação do objeto.

\subsection{Diferentes Fazeres presentes no discurso do monitor}

Nós aplicamos categorias da lingüística próprias da análise da finalidade do discurso especializado (Charaudeau, 1994) para definir a atividade socio-cognitiva predominante de cada episódio. Elas são definidas como a intenção presente no discurso do monitor para que os participantes executem uma tarefa enunciada. Estas atividades são agrupadas em três categorias de fazeres listadas a seguir.

a) Fazer Saber (FS), atividades consistindo em engajar os participantes na reflexão sobre os acontecimentos observados propondo questões ou explicações (Cf. quadro 2).

Quadro 2: Fazer Saber (explicação do sistema de propulsão)

77. A : Aí, a pólvora de canhão como disse/como disse Bernard/ isto queima e, depois ao mesmo tempo, faz uma explosão e aí ela empurra a bala. Aí o que acontece é que efetivamente tem uma pequena pressão criada/ porque a bala está no fundo do canhão/ e queimando/ a pólvora/ ela precisa de espaço/ ela tem vontade de tomar o espaço/e então ela vai empurrar/ ela vai empurrar a bala da frente dela. Aí/ quando vocês pensam isto/ vocês podem pensar que tem qualquer coisa no outro sentido/ ao invés de empurrar a bala/ a gente empurra o canhão (risos). Não!

78.E : Não o canhão, ele vai cair na água depois/

79.A : Sim se ele está sobre um barco!

80.E : Sim.

81.A : E/ Eu tenho certeza que os pesquisadores dizem: Ah, sim !

Nesta passagem (turnos 77-81) o monitor retoma o discurso do participante (Bernard) 
para em seguida introduzir uma explicação empregando a palavra pressão:

(77) A: Como disse Bernard isto (a pólvora) queima e, depois, ao mesmo tempo, faz uma explosão e aí ela empurra a bala. Aí o que acontece efetivamente é que existe uma pequena pressão...

A intenção do monitor é explicar o sistema de propulsão do micro foguete baseando-se no princípio da ação e reação. Os participantes estão assentados em um círculo (OC) e o monitor não utiliza nenhum elemento do cenário para manipulação.

b) Fazer Fazer (FF), atividades consistindo em engajar os participantes a manipular os objetos por exemplo para cortar, colar, pintar... (Cf. quadro 3).

Quadro 3: Fazer Fazer (instalação do sistema de disparo)

423.A : Bom isto/eu posso ligar em qualquer lugar?

424.Bernard : Não, não tem um jeito mais fácil de fazer !

425.A : Qual ?

426.Bernard: Apenas um fio de cada lado/ dois fios com de cada lado uma garra jacaré 427.A : Legal!

428.Bernard : A gente põe uma garra jacaré na bateria e uma garra jacaré no disparador e uma outra garra jacaré na bateria e outra garra jacaré no faiscador. (Bernard manipula os fios)

Nesta passagem (turnos 423 - 428) o monitor incentiva Bernard a instalar o sistema de disparo cedendo-lhe o espaço de ação.

423-A: Bom isto/ eu posso conectar em qualquer lugar?

424-Bernard: Não, não tem um jeito mais fácil

425-A: Qual ?

A intenção do monitor nesta passagem é levar os participantes a manipularem o sistema de disparo do micro foguete. Os participantes estão em pé em torno do sistema (OU) procurando tocar seus elementos (fios, bateria, garras jacaré, faiscador).

b) Fazer Perceber (FP), atividades consistindo em engajar os participantes a observar os acontecimentos apelando para diferentes sistemas sensoriais como o olfato, audição...(Cf. quadro 4). 


\section{Quadro 4 : Fazer Perceber (observação do funcionamento do sistema de disparo)}

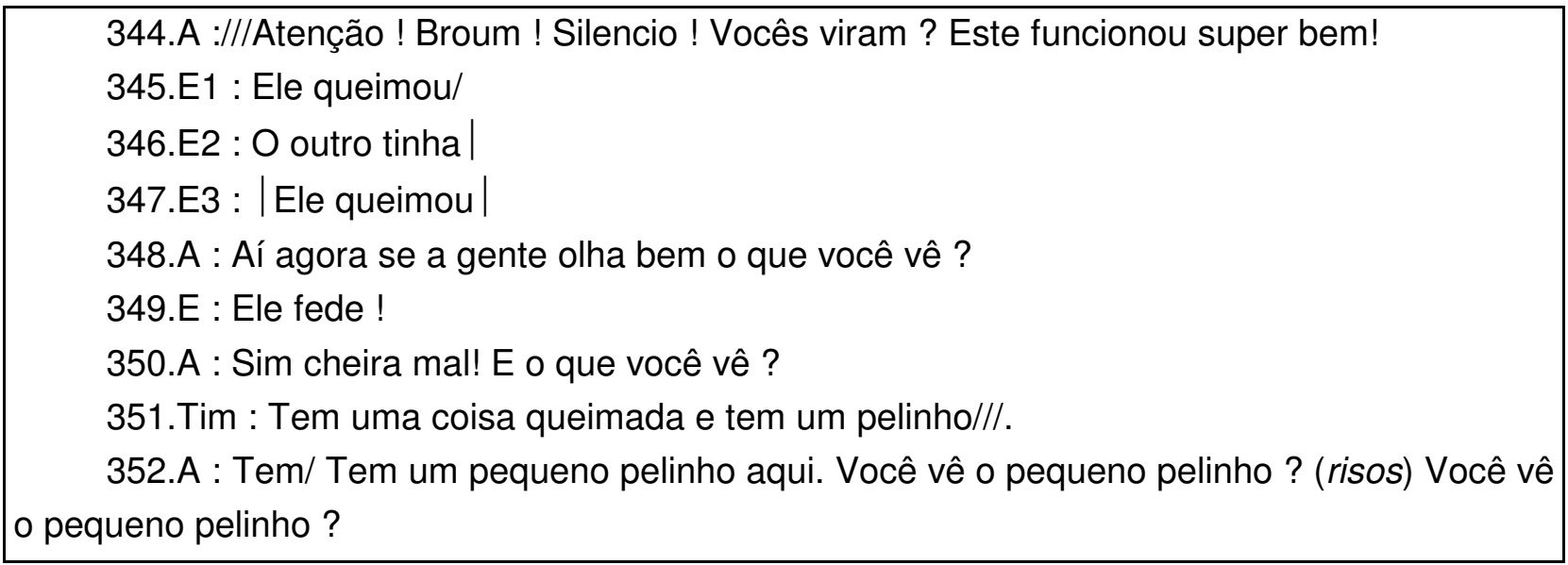

Nesta passagem (turnos 344 - 352) através de uma onomatopéia (broum!) o monitor chama a atenção para a faísca produzida no sistema de disparo do micro foguete. A intenção do monitor, é despertar os elementos sensitivos do sistema de disparo: a pequena faísca, 0 rompimento do fio de tungstênio no faiscador, o odor resultado da combustão...

A análise da sucessão dos episódios de cada etapa permite a construção do protocolo efetivo da seqüência.

\section{Análise da etapa de apresentação}

Em todas as seqüências analisadas constatamos que o posicionamento dos participantes, face ao objeto técnico a ser construído bem como do conhecimento científico a ser apresentado, ocorre durante a etapa de apresentação da seqüência. A análise proposicional foi o principal instrumento utilizado para caracterizar os saberes presentes nesta etapa.

No sentido gramatical uma proposição contém o sujeito, o verbo e seus complementos (verbais ou nominais). Em nosso caso, empregamos como unidade de análise o sentido presente nos enunciados do monitor, algumas vezes constituído por uma proposição gramatical incompleta como no exemplo abaixo.

285. A: a. eu mostrarei para vocês,

b a gente vai,

c a gente abrirá,

d a gente abrirá daqui a pouco

e e depois eu mostrarei como, como é por dentro.

Destacamos, sistematicamente, todas as proposições relacionadas a um verbo de ação (pegar, tocar, fazer...) e aos elementos do objeto técnico à ser construído (ogiva, fios, garras 
jacaré...). Em relação às proposições em que se descreve uma ação, nós interessamos pela definição do sujeito (eu, você, a gente, nós...). Em relação às proposições sobre o objeto técnico, nós procuramos identificar quais são os elementos descritivos usados para caracterizálo. Estas proposições foram agrupadas em quatro categorias: nominação $(\mathrm{N})$, localização $(\mathrm{L})$, qualificação(Q) e função (F) (Cf. quadro 5).

Quadro 5: Discurso do monitor de descrição do objeto técnico

\begin{tabular}{|c|l|l|c|}
\hline Proposição & $\begin{array}{c}\text { Elemento do } \\
\text { objeto técnico }\end{array}$ & Enunciado & Categoria \\
\hline $473(\mathrm{~b})$ & garra jacaré & esta é uma outra garra & $\mathrm{N}$ \\
260 (b) & pilha & sim, a pilha ela está aqui & $\mathrm{L}$ \\
371 (b) & propulsor & não é grande . & $\mathrm{Q}$ \\
& & a garra que vai prender o disparador & $\mathrm{F}$ \\
\hline
\end{tabular}

Dois episódios que se referem ao lançamento do propulsor do micro foguete foram analisados (476 turnos num total de 1216 falas do monitor e dos participantes transcritos). Descartamos as proposições onde o discurso do monitor é incompreensível assim como aquelas que visavam uma interação com outros adultos presentes no cenário. Assim, estes episódios contêm 314 proposições onde o monitor explica o princípio de funcionamento do micro foguete.

\section{Alguns resultados}

\subsection{O protocolo efetivo da seqüência}

O cenário da seqüência é composto de configurações espaciais múltiplas: organização linear, em círculos, centrada em objetos e em duplas assim como configurações livres. A cronologia da seqüência evidenciada através do protocolo efetivo (Cf. quadro 6) mostra que, ao lado da atividade principal (conceber, construir e lançar o micro foguete), somam-se atividades experimentais que permitem os participantes compreenderem os princípios gerais de construção do objeto técnico (por exemplo o lançamento de um tubo de aspirina e de uma mangueira de jardim para explicar o princípio de ação e reação) e desenvolverem habilidades manuais: recortar, perfurar, colar... 
Quadro 6: Fragmento do protocolo efetivo de 3 episódios

\begin{tabular}{|c|c|c|c|c|c|}
\hline Etapa & \begin{tabular}{|c|} 
Duração \\
(em \\
min)
\end{tabular} & $\begin{array}{c}\text { Configuração } \\
\text { espacial }\end{array}$ & Episódio & $\begin{array}{l}\text { Material e/ou } \\
\text { equipemento }\end{array}$ & Atividade do monitor \\
\hline \multirow{3}{*}{ 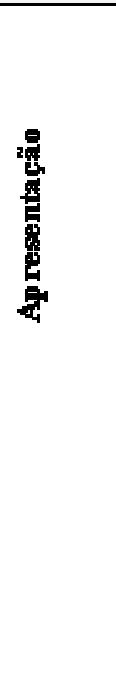 } & 18 & $\begin{array}{c}\mathrm{CL} \\
\text { (Configuração } \\
\text { livre) }\end{array}$ & A pólvora & & $\begin{array}{l}\text { Propor perguntas sobre } \\
\text { a pólvora (FS) }\end{array}$ \\
\hline & 16 & $\begin{array}{c}\text { CL } \\
\text { (Configuração } \\
\text { livre) }\end{array}$ & $\begin{array}{l}\text { Preparação } \\
\text { do } \\
\text { lançamento } \\
\text { do propulsor }\end{array}$ & $\begin{array}{l}\text { disparador, } \\
\text { bateria, } \\
\text { faiscador, } \\
\text { fio, garra jacaré }\end{array}$ & $\begin{array}{l}\text { Propor perguntas sobre } \\
\text { o sistema de alumagem } \\
\text { (FS) } \\
\text { e sobre o sistema de } \\
\text { propulsão (FS) }\end{array}$ \\
\hline & 30 & \begin{tabular}{l}
\multicolumn{1}{c}{ OL } \\
(Organização \\
linear)
\end{tabular} & $\begin{array}{l}\text { Teste do } \\
\text { propulsor }\end{array}$ & $\begin{array}{l}\text { propulsor, } \\
\text { disparador, } \\
\text { algodão }\end{array}$ & $\begin{array}{l}\text { Fazer funcionar o } \\
\text { disparador (FP) } \\
\text { Fazer funcionar o } \\
\text { propulsor (FP) }\end{array}$ \\
\hline
\end{tabular}

O protocolo efetivo da seqüência é uma ferramenta que descreve a seqüência em duas dimensões. A primeira, cronológica, nos informa sobre a evolução da atividade principal (conceber, construir e lançar o micro-foguete) no tempo e no espaço. Esta dimensão evidencia a organização da configuração espacial do grupo em função dos diferentes fazeres propostos pelo monitor dentro dos episódios. Essa mesma organização foi observada em outros estudos sobre o mesmo objeto o que nos indica a existência de um protocolo implícito que caracterisa 0 procedimento fornecido pela associação a seus monitores (Tissot, 1998 e Prézeau, 1999). O protocolo explicita também a presença de atividades experimentais complementares que visam a explicação dos princípios gerais de funcionamento do objeto técnico. Logo, a seqüência não visa unicamente a construção do objeto mas a apresentação de um conhecimento físico sobre o objeto técnico.

A segunda dimensão, no interior das etapas e dos episódios, nos informa a relação entre a organização no tempo e no espaço dos fazeres do monitor. Esta leitura mostra que, durante as atividades de Fazer Fazer, os participantes são autônomos em sua configuração espacial mesmo se o trabalho em duplas é sugerido pelo monitor. Ele reúne os participantes no momento das atividades de Fazer Saber e de Fazer Perceber, o que facilita a discussão de temas relacionados aos fenômenos apresentados. A organização linear é restrita às questões de segurança dos participantes nos momentos de lançamento do propulsor e do micro foguete.

\subsection{Os fazeres e os saberes no discurso do monitor}

O discurso do monitor, dentro do conjunto da seqüência, mostra uma intenção de coordenar os participantes em suas atividades de Fazer Fazer ( 9 atividades sobre um total de 
23 listadas). Entretanto, esta ligeira predominância sobre as atividades de Fazer Saber (8 sobre 23) e de Fazer Perceber (6 sobre 23) nos interroga sobre a natureza dos saberes presentes na seqüência. O discurso do monitor, dentro desses episódios, apresenta uma "didaticidade" (Beacco, 1995), pois ele tem uma intenção de possibilitar aos participantes o contato com um novo saber sobretudo de ordem técnica (Fazer Fazer) e conceitual (Fazer Saber) .

Para ultrapassar o quadro descritivo dos fazeres do monitor nestes dois episódios já citados - preparação e lançamento do propulsor- apresentamos um outro tipo de análise que identificar o saber presente no discurso do monitor. Inicialmente, desenvolvemos uma análise a priori dos conceitos científicos relacionados com o funcionamento do propulsor, o que nos possibilitou a criação de um léxico do tema (combustão da pólvora, principios de ação e reação, descarga elétrica). Este léxico foi utilizado como indicador para a seleção das proposições. Por exemplo, a palavra pressão destaca o turno $281^{6[6]}$, onde o monitor mostra os diferentes orifícios (um grande e um pequeno em extremidades opostas) do propulsor :

281 A: a. é o que você dizia efetivamente

b. se tem um pequeno buraco tem mais pressão.

Sobre esta primeira entrada, que totaliza 9 proposições, constatamos que o monitor emprega este léxico sem um desenvolvimento conceitual do mesmo limitando-se à enunciação das palavras. Por exemplo, no turno $290^{7[7]}$,o monitor mostra o circuito montado do disparador e identifica todo o circuito como o sistema elétrico:

\section{A : a. Então o disparador é como um pequeno fósforo \\ b. como você dizia Tim \\ c. e funciona com o sistema elétrico.}

A segunda entrada que utilizamos toma o verbo como indicador nas proposições. Isto nos conduziu a estabelecer três categorias:

Descrição do objeto técnico : as proposições que descrevem o objeto, ou parte dele,

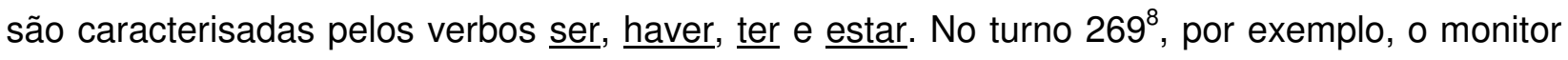
descreve o propulsor.

\section{A: a. a pólvora ela já está la dentro}

\footnotetext{
6[6] 281. A : (a) c'est ce que tu disais effectivement

(b) s'il y a un petit trou il y a plus de pression..

7[7] 290 Alors les allumeurs c'est la petite allumette

(b) comme tu disais Tim

(c) et ça fonctionne avec un système électrique

${ }^{8} 269$ A : (a) La poudre elle est déjà dedans !

(b) Le propulseur il est tout de suite fabriqué/

(c) moi, je , moi je ne fais plus rien///
} 


\section{b. o propulsor ele é todo fabricado \\ c. eu, eu não faço mais nada}

A descrição do objeto técnico se constitui de 66 proposições. O monitor qualifica este objeto (ele é grande, tem um pequeno buraco, está fixado nos sistema elétrico ...) sendo atento ao nomear todos seus elementos constitutivos (disparador, fios, garras jacaré, pilha, ogiva, pára-quedas...).

Contrato de manipulação : as proposições que determinam as regras de utilização do material, produtos e equipamentos são caracterizadas pelos verbos dever e precisar. Como no turno $368^{9[9]}$, o monitor executa a montagem do sistema de disparo do propulsor. Uma vez que os participantes gostariam de unir os fios diretamente aos polos da bateria sem utilisarem as garras jacaré.

368 A: a. Sim, mas não se pode esquecer

b. que é necessário alguma segurança [né]

c. então / para as garras jacaré, está bom !

O contrato de manipulação (51 proposições) é definido por regras de segurança com o manejo com o sistema de disparo e com o propulsor.

Gestão da ação: As proposições relacionadas às ações dos atores sobre os objetos são caracterizadas pelos verbos colocar, fazer, pôr... Nos turnos $401^{10[10]}$ e 402 realçamos a dinâmica do discurso de ação marcado pela contextualização das proposições. Bernard e o monitor estão montando o sistema de disparo conectando as extremidades dos fios à bateria $\mathrm{e}$ ao diaparador. O monitor coordena Bernard explicitando a ação:

401 Bernard : isto, a gente* põe sobre o mesmo fio, né !

$402 \mathrm{~A}$ : Então eu ponho isto sobre a bateria!

403 Bernard : a. Não, não/ isto você põe sobre a bateria

b. e isto será sobre o disparador!

O discurso do monitor é fundamentalmente referente à gestão da ação (139 proposições), seja para engajar os participantes na execução das tarefas, seja para explicitar suas próprias ações.

\footnotetext{
${ }^{9}$ 368. A : (a) Oui mais il ne faut pas oublier.

(b) qu'il faut un peu de sécurité quand même/

(c) alors/ pour les pince- crocodiles, c'est bon !

100401 Bernard : ça, on* le met sur le même fils, quoi !

$402 \mathrm{~A}$ : Donc je mets ça sur la batterie!

403 Bernard: (a) Non, non/ ça tu le mets sur la batterie
} 
As outras 49 proposições do monitor incluem a gestão de elementos lúdicos extremamente importantes no desenvolvimento da seqüência, mas que não foram discutidas ao longo deste artigo.

Em resumo, o discurso do monitor é fortemente contextualisado pela especificidade da construção do objeto técnico através de um discurso de ação (44\% das proposições). Assim, a construção de um saber sobre o objeto passa pela ação norteada pela descrição (21\%) e a definição de regras de manipulação (16\%). Se considerarmos que a enunciação de um vocabulário científico é um indicador de um saber teórico utilisado como referência pelo monitor, esta seqüência apresenta $3 \%$ de proposições ligadas ao conhecimento científico. Entretando segundo Layton (1994:126), nós podemos definir um saber teórico de outra natureza: o saber tecnológico. Para o autor, este saber é estruturado pela tensão entre as exigências de um concepção funcional e de restrições específicas do contexto de produção de um objeto técnico. Ora, nos episódios analisados o monitor procura transmitir aos participantes os elementos funcionais na descrição do objeto técnico e as regras específicas de manipulação do propulsor ou seja o contrato de manipulação. Em conseqüência, o saber teórico em questão nestes episódios possui uma natureza próxima à definição de um conhecimento tecnológico. Podemos assim, propor o discurso de descrição associado ao contrato de manipulação e a definição do vocabulário totalisam $40 \%$ das proposições. Voltando ao modelo de Resnik (1989) podemos concluir que estes indicadores descrevem o saber teórico do monitor enquanto que seu discurso de ação (44\% das proposições) podem ser pensados como indicador de seu saber prático.

\subsection{A estratégia de engajamento na ação}

Nossos dados indicam que o monitor desenvolve em sua prática discursiva uma estratégia de engajamento dos participantes de modo a desenvolver este protocolo. Definiremos tal estratégia como a margem de manobra do monitor para aplicar, dentro do cenário proposto, o protocolo prescrito pela associação.

Como primeira aproximação da estratégia de engajamento dos participantes na seqüência analisamos o discurso de ação e de descrição do monitor. Para enunciar as ações, o monitor se dirige ao grupo mais freqüentemente na forma impessoal (on, 73 vezes) ${ }^{11}$. O agente da ação designado pela primeira pessoa (je, 29 vezes) ${ }^{12[12]}$, segunda pessoa (tu, 26 vezes) ou pelo grupo (vous,11 vezes) são também utilizados. Nós pensamos que este modo de linguagem do monitor é semelhante àquele utilizado no discurso publicitário, identificado por Charaudeau (1994) como um modo de criar um ambiente descontraído e uma cumplicidade afetiva entre os participantes. A título de exemplo destacamos a fala do monitor onde os participantes são convidados a fazer a contagem regressiva para o lançamento do micro foguete:

(b) et ça ce sera sur l'allumeur !

${ }_{11}$ "On" correspondente em protuguês a "a gente".

$12 \mathrm{Je}(\mathrm{eu})$ 
707 A: Tem um que começa, em seguida todo mundo em coro, bem forte, história de mostrar a todo mundo que a gente faz foguetes/ que a gente se diverte bem. Então a gente faz a contagem regressiva, e, a zero, a pessoa que é encarregada de lançar, fuzz. A gente começa. $^{13}$

A análise proposicional da descrição do objeto mostra que o monitor enfatiza a "qualificação" (42\% das proposições) dos elementos constituintes do objeto (ele é grande, é flexível, tem um furo...) e igualmente a "nomeação" (35\% das proposições) de todos os elementos constitutivos do objeto técnico (disparador, fios, garras jacaré...). Nos episódios analisados, a exemplo da descrição do sistema de propulsão (cf. tabela 2), nos indica uma seqüência que visa a apresentação do objeto técnico centrada na "nomeação" e na "qualificação" de seus elementos constitutivos.

Tabela 2 : Discurso do monitor sobre o objeto (sistema de propulsão)

\begin{tabular}{|c|c|c|c|c|c|}
\hline Objeto ou elemento & Nomeação & Localização & Qualificação & Função & TOTAL \\
\hline fios & 1 & 3 & 6 & 3 & 13 \\
disparador & 2 & 0 & 7 & 1 & 10 \\
propulsor & 2 & 1 & 7 & 0 & 10 \\
garra jacaré & 6 & 0 & 3 & 1 & 10 \\
pilha & 1 & 1 & 1 & 2 & 5 \\
faiscador ou fósforo & 1 & 1 & 1 & 0 & 3 \\
filamento & 1 & 0 & 0 & 1 & 2 \\
boîtier (caixa de & 3 & 0 & 2 & 1 & 6 \\
comando) & & & & & \\
bateria & 1 & 0 & 1 & 0 & 2 \\
transformador & 2 & 0 & 0 & 0 & 2 \\
foguete & 3 & 0 & 0 & 0 & 3 \\
TOTAL & 23 & 6 & 28 & 9 & 66 \\
\hline
\end{tabular}

\section{Conclusão}

O objetivo de nosso trabalho foi descrever e caracterizar os saber teóricos e práticos presentes no discurso do monitor ao longo de uma seqüência de construção de um objeto técnico (o micro foguete) em um espaço não escolar. Nós observamos, aplicando os mesmos

\footnotetext{
${ }^{13} 707 \mathrm{~A}$ : Il y en a un qui commence ; ensuite tout le monde en chœur, très fort, histoire de montrer à tout le monde qu'on fait des fusées/ qu'on s'amuse bien. Donc on fait le compte à rebours, et à zéro la personne qui est occupée de lancer fuzz . Là on commence.
} 
indicadores em outras seqüências, que existe uma regularidade na cronologia e na gestão do espaço. Uma função do monitor é gerenciar o espaço interior e exterior à sala, em suas configurações múltiplas, organizando o trabalho dos participantes em pequenos grupos e em duplas. A construção do objeto técnico é permeada de atividades experimentais que tentam explicar os diversos processos e dispositivos constitutivos do micro foguete. A definição do protocolo efetivo nos permite indicar a inclusão e/ou exclusão dessas atividades experimentais e pode ser um indicador do saber prático do monitor com relação ao enunciado das tarefas. A análise da finalidade do discurso do monitor destaca uma ligeira predominância das atividades socio-cognitivas ligadas à manipulação (Fazer fazer) sobre as demais (Fazer saber e Fazer perceber). Contudo, destacamos que o discurso do monitor contém ainda atividades lúdicas e de organização do trabalho coletivo que não foram analisadas neste artigo. A predominância da manipulação poder ser atribuída ao objetivo central e à complexidade do objeto construído nesta seqüência. Primeiramente, uma seqüência experimental proposta em um espaço não escolar tem como objetivo central a "iniciação", a "sensibilização" e não a construção de um conhecimento científico ou tecnológico. Assim, os princípios de funcionamento do micro foguete, que dificilmente poderiam ser explicados a um grupo desta faixa etária em tão pouco tempo (8h), não constituem o centro de atenção do monitor. O saber teórico de referência utilizado pelo monitor dentro da seqüência é o conhecimento tecnológico raramente apresentado em espaços escolares. De fato, a seqüência se inscreve em um contexto de "lazer científico" onde os objetivos são distintos daqueles presentes nas práticas escolares. A apresentação de um vocabulário científico e tecnológico visa despertar um nova rede de significados que poderá ser retomada em um outro contexto. A análise do discurso descritivo do objeto técnico e de suas partes constitutivas indica que ele é centrado na nomeação e na qualificação reforçando o caráter de iniciação ao conhecimento científico e tecnológico. Enfim, o elemento motivador da atividade é a construção, o teste do objeto e o sucesso do lançamento do micro foguete, sem o qual o discurso do monitor seria vazio de significado.

Ao longo da primeira etapa da seqüência nos episódios analisados, o discurso do monitor é caracterizado pelas formas impessoais e pela progressiva introdução das falas dos participantes. O monitor gradualmente interpela individualmente os participantes (2a pessoa do singular) abrindo assim um espaço de fala e de ação dos participantes.

Os instrumentos que construímos informam sobre a maneira que o monitor gerencia a seqüência : seu saber prático. Mesmos os resultados sendo locais podemos supor que existem regularidades neste saber e que é possível uma sistematização da estratégia de engajamento dos participantes. Propomos que o discurso de ação do monitor indica um modo de engajamento coletivo empregando a primeira pessoa do plural ou formas impessoais como agente das ações.

Através deste estudo de caso, definimos alguns indicadores do saber profissional do monitor. Este saber é constitutivo de uma prática educativa emergente onde as relações de mediação de conhecimento científico são importantes mas pouco investigadas. Tais estudos 
fornecem meios de enfrentar a questão de formação profissional de educadores para espaços não escolares e consequentemente propor novas formas de formação continuada do cidadão.

\section{Referencia Bibliográficas}

ANSTJ (1997) Microbe. Carnet de charge des animateurs scientifiques ANSTJ. Mineo. Riz Orangis.

BEACCO, J-C., MOIRAND, S. (1995) Autour des discours de transmission de connaissance. Les analyses du discours en France. Langages, 117, pp. 32-53.

CHARAUDEAU, P. (1994) Catégories de langue, catégories de discours et contrat de communication, parcours linguistiques de discours spécialisés. Berne: Peter Lang.

GAUTIER, G. (1989) L'association nationale sciences techniques jeunesse un projet pédagogique et le contexte micro-social de son élaboration. In: ASTER Les sciences hors de l'école, 9, pp.85-116.

GIORDAN, A., SOUCHON, C., CANTOR, M. (1993) Évaluer pour innover: musée, médias et école. Nice: Z'édition.

GRIZE, , J,-B. (1996) Savoirs théoriques et savoirs d' action: point de vue logiquediscursif. In : Barbier, J-M (org.). Savoirs théoriques et savoirs $d^{\prime}$ actionParis: P.U.F.

LAYTON, D. (1994) Education scientifique et action: les relations entre les sciences enseignées à l'école et la pratique. In : ASTER: La didactique des sciences en Europe, 19, pp.117-155.

MARTINAND, J-L. (1986) Connaître et transformer la maitière. Berne: Peter Lang.

NASCIMENTO, S.S (1999) L'animation scientifique: essai d'objectivation de la pratique des associations de culture scientifique et technique Française. Tese de doutorado. Université Pierre et Marie Curie, Paris 6.

PLETY, R. (1993) Éthologie des Communications Humaines. Aide-mémoire méthodologique. Lyon: Presses Universitaires de Lyon.

PREZEAU, O (1999) Méthodologies d'observation et $d^{\prime}$ analyse $d$ ' une séquence d' anómati scientifique de l' ANSTJ Memória de DEA- Didactique des Disciplines: Sciences et Techniques Physiques et Chimiques. Universidade de Paris 7.

RAISKY, C. (1996) Doit-on en finir avec la transposition didactique ? essai de contribution à une théorie didactique. In: C. Raisky et M. Caillot (Eds) Au-delà des didactiques, le didactique. Débat autour de concepts fédérateurs. Bruxelles: De Boeck Université.

TISSOT, F. (1998) Transposition de recherche : Peut-on expliciter une stratégie d'animation à partir de l'analyse du discours d'un animateur ? Memória de DEA- Didactique des Disciplines: Sciences et Techniques Physiques et Chimiques. Université Denis Diderot Paris 7. 